\title{
Polyploidization of transplanted cardiac myocytes
}

\author{
V. Ya. Brodsky ${ }^{1}$, B.M. Carlson ${ }^{2}$, A.M. Arefieva ${ }^{1}$ and I.A. Vacilieva ${ }^{1}$ \\ 'Institute of Developmental Biology, Academy of Sciences of the U.S.S.R., Moscow, U.S.S.R. \\ and 2 Departments of Anatomy and Biology, University of Michigan, Ann Arbor, MI, U.S.A.
}

(Accepted 27 July 1988)

Pieces of cardiac ventricular tissue of late embryonic or 1-day postnatal rats, implanted beneath the kidney capsule of adult syngeneic hosts, formed viable, beating transplants. These transplants were investigated over a 40-day postoperative course. In the transplants, cellular binucleation and nuclear polyploidization occurred according to the same schedule as in the heart in situ. The composition of the classes of myocytes was identical both in the hearts in situ and in transplants, but the number of non-diploid myocytes in the intact heart reached $90 \%$, whereas in transplants it varied from 30 to $60 \%$. In contrast to the heart in situ, myocytes in transplants grew feebly after the phase of polyploidization. From these data one can conclude that under conditions of transplantation the temporal sequence of cellular binucleation and nuclear polyploidization follows the normal course, but that a greater number of myocytes remain in a diploid state than is the case in the normal heart. The growth of cardiac myocytes seems to be related to their level of function.

Cardiac myocyte; Differentiation of cells in situ and in transplants; Postnatal development; Cellular polyploidization

\section{Introduction}

Polyploidization is a constant and early event in postnatal development of the heart in mammals (Rakusan, 1984; Brodsky and Uryvaeva, 1985). The ventricles of the heart of newborn mice are formed almost exclusively of diploid myocytes. Cell divisions still occur during the first three to four days of life, and the number of myocytes increases by $20-25 \%$. Then, during the course of one to two weeks, about $90 \%$ of the myocytes

\footnotetext{
Correspondence address: Bruce Carlson, Department of Anatomy, 4622 Medical Science II Building, University of Michigan, Ann Arbor, MI 48109, U.S.A.
}

become polyploid, mainly binucleate $[2 n(c) \times 2$, where $n=$ the number of chromosomes and $c=$ the quantity of DNA in a haploid set]. At the same time other cells increase their ploidy up to $8 n(c)$ $\times 2$ and $16 n$ (Brodsky et al., 1980, 1985b). At three to four weeks after birth in mice and rats mitosis has practically ceased (Rumyantsev, 1977, 1981).

What is the cause of the transition from the complete mitoses of myocytes during the first days of postnatal life to the incomplete, special differentiation of cells by polyploidization or their incomplete mitosis, and finally the complete cessation of mitosis? Is this caused by external factors, such as the distinctive hormonal environment of the newborn, changes in the hemodynamic load in 
connection with the rapid growth of the animal or by the development of the specific innervation of the heart?

In order to answer this question, we employed a surgical model in which pieces of ventricular tissue of embryonic or 1-day postnatal hearts were transplanted under the kidney capsule of syngeneic adult rats. In this model, ventricular cells that were still in the phase of mitotic division were placed in an environment where they were removed from many of the environmental factors (hemodynamic load, humoral and neural factors) to which they would have been exposed in situ. Several types of cellular responses to the transplantation are possible: (1) mitosis is blocked at once, and the cells remain diploid; (2) complete division continues, and the cells also remain diploid; (3) at some time complete mitosis changes to incomplete, and the cells undergo binucleation and polyploidization. The last variant would suggest the presence of an internal program that operates independently from some of the external influences that act upon developing cardiac myocytes.

\section{Materials and Methods}

This study was conducted on F-455 rats (derived from the Wistar strain) that had been inbred at the University of Michigan for 100 generations. Pieces of ventricles from the hearts of 20-day embryos or 1-day postnatal rats were grafted beneath the capsule of adult rats of the same strain. During the operation, the hosts were anesthetized with ether. Following transplantation, the rats were placed on oral terramycin for a week and maintained under standard conditions.

From 4 to 41 days postoperatively the transplants, along with small fragments of renal tissue, were removed and fixed in 10\% buffered ( $\mathrm{pH} 7.0$ ) formalin for 20-30 days. Then the pieces of tissue were dissociated into individual cells in a 50\% $\mathrm{KOH}$ solution; the method of treatment and the results concerning the preservation of DNA and proteins was summarized earlier (Brodsky et al., $1980,1985 b$ ). Smears were stained by the Feulgen method and by naphthol yellow. The content of
DNA and protein in the isolated myocytes was measured on a Vickers M-86 scanning microdensitometer. Photometry of the nuclei was carried out with a $100 \times$ objective in the region of absorption of DNA-Fuchsin (Feulgen), about 580 $\mathrm{nm}$. For measurement of the protein content, photometry of the entire cell was carried out, using a $20 \times$ objective in the spectral region of $445 \mathrm{~nm}$, that is close to the maximum absorption of naphthol yellow and with only weak absorption of DNA-fuchsin (see Tas et al., 1980). $\left[{ }^{14}\right.$ C]Thymidine (New England Nuclear, with a specific activity of $55.2 \mathrm{mCi} / \mathrm{mM}$ ) was injected intraperitoneally $(1 \mu \mathrm{Ci} / \mathrm{g}$ body wt) into the recipient rats with 4-day transplants. The transplants were fixed either $3 \mathrm{~h}$ or 30 days after injection of the thymidine. The Feulgen-stained preparations of the isolated cells were coated with type $M$ liquid emulsion (U.S.S.R.) and exposed for 14 days.

\section{Results}

A histogram of the amount of DNA in cardiac myocytes of the newborn rat (Fig. 1) shows a distribution typical for a dividing population of diploid cells, i.e. the majority of cells have a diploid (2c) quantity of DNA and a few an intermediate amount, between $2 c$ and $4 c$. At this time one can consider as truly polyploid only the binucleated cells, having in total a tetraploid genome; these consist of $1-3 \%$ of the population of myocytes. After a month the cardiac ventricles contained about $90 \%$ polyploid myocytes, of which $75-80 \%$ were binucleated $2 c \times 2$ cells (see Tables I and II). Myocytes with a high degree of ploidy were far fewer than in the mouse.

Once established, the myocytes within the ventricular grafts beat rhythmically. The beating of the grafts was readily visible beneath the kidney capsule. Myocytes in transplants differed from myocytes in situ by their small size and mass. After a month the mean content of protein in the myocytes of transplants exceeded that in the original myocytes of the 1-day heart only by a factor of 2 , whereas in the ventricle in situ, the myocytes increased by a factor of more than 6 times (Table III). Up to 14 days, the myocytes in transplants 
TABLE I

Percentage of myocytes with different numbers of nuclei in the ventricle of the heart and in transplants

\begin{tabular}{|c|c|c|c|c|c|c|}
\hline \multirow[t]{2}{*}{ Tissue } & \multirow{2}{*}{$\begin{array}{l}\text { Age } \\
\text { (days) }\end{array}$} & \multirow{2}{*}{$\begin{array}{l}\text { No. of } \\
\text { samples }\end{array}$} & \multirow{2}{*}{$\begin{array}{l}\text { No. of } \\
\text { myocytes }\end{array}$} & \multicolumn{3}{|l|}{ Percent } \\
\hline & & & & $\begin{array}{l}\text { Mono- } \\
\text { nucleated }\end{array}$ & Binucleated & $\begin{array}{l}\text { Tetra- } \\
\text { nucleated }\end{array}$ \\
\hline \multirow[t]{3}{*}{ Ventricles } & 20-day embryos & 3 & 5525 & 99.8 & 0.2 & - \\
\hline & 1 & 2 & 1034 & 97.8 & 2.2 & - \\
\hline & $30-40$ & 3 & 2486 & 11.5 & 86.9 & 1.6 \\
\hline Transplants & $30-41$ & 5 & 3281 & 59.7 & 40.2 & 0.1 \\
\hline
\end{tabular}

have essentially not grown. The nuclei of cells in situ have usually grown far apart from one another (thus explaining why in sections of cardiac myocytes these cells were often considered to be mononuclear, diploid cells). In transplants the nuclei of single cells were usually close together, not infrequently touching one another. The nuclei of mammalian cells were sometimes stretched out

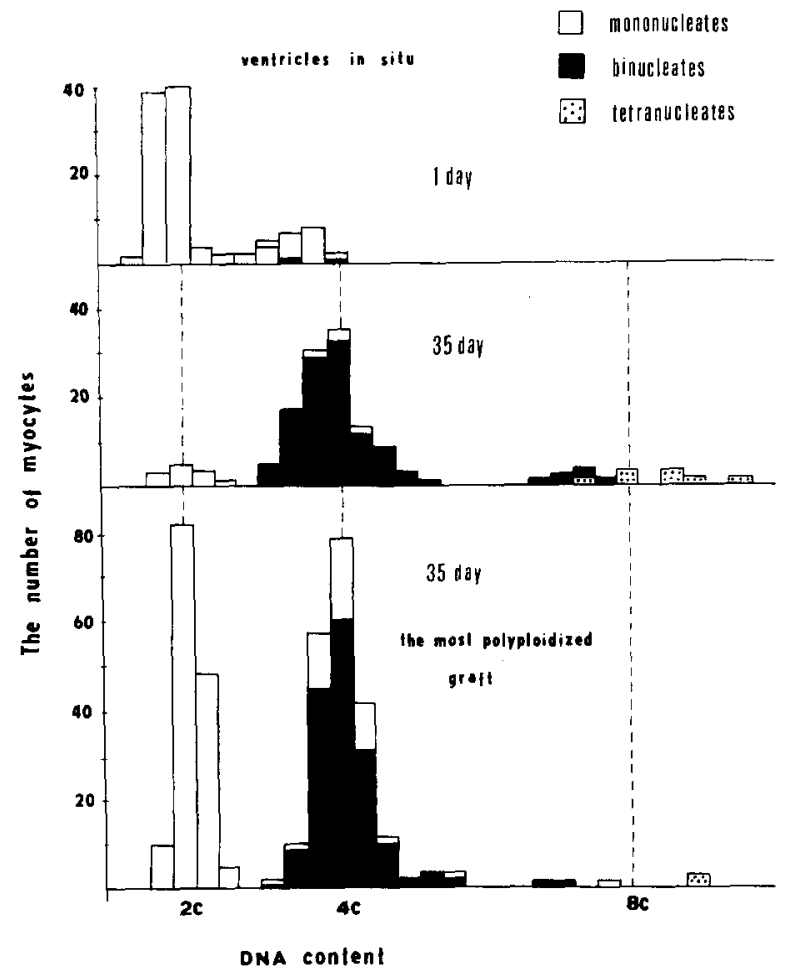

Fig. 1. Histograms of the amount of DNA ( $c=$ haploid level) in mononucleated, binucleated and tetranucleated ventricular myocytes of 1- and 35-day rats and in the most polyploidized graft. or even dumbbell-shaped. Cells in transplants were not only shortened; often they did not possess a normal cylindrical form, but rather were char-

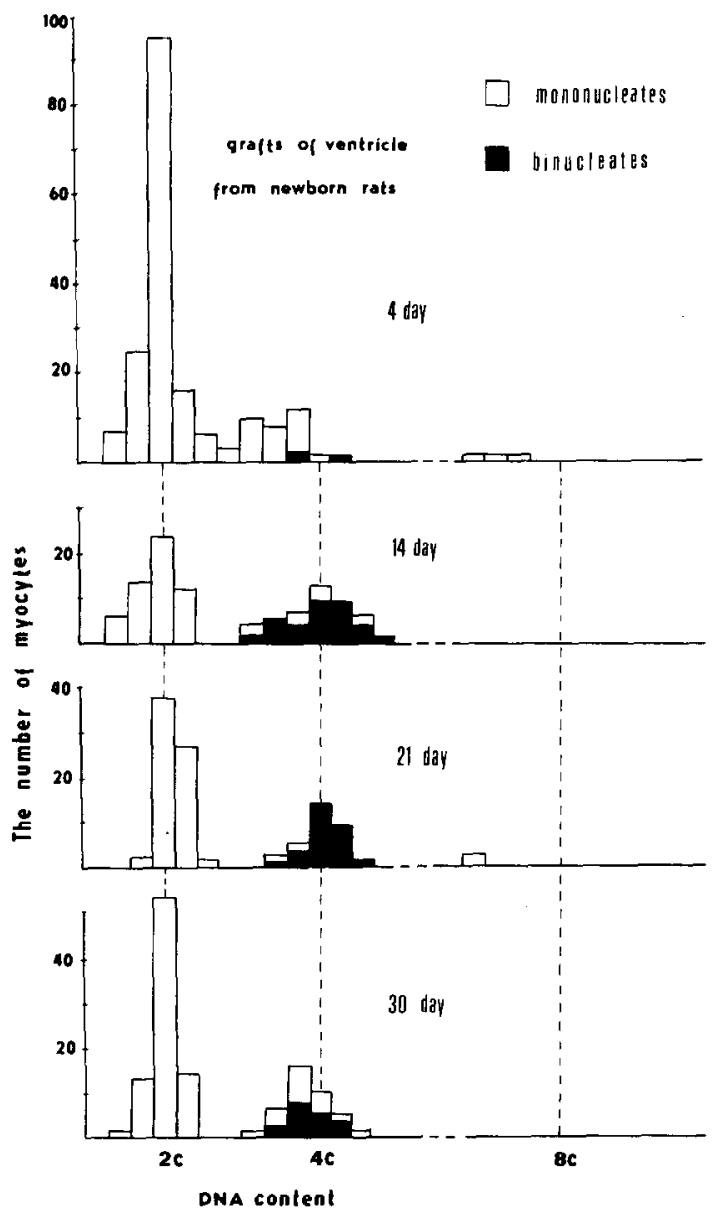

Fig. 2. Histograms of the amount of DNA in myocytes from transplants of cardiac ventricular tissue of 1-day rats, surviving for different periods under the kidney capsule in syngeneic adult rats. The dashed lines refer to the content of DNA in diploid nephrons $(2 c)$ and its multiples. 
TABLE II

Classes of ploidy ( $c=$ haploid content of DNA) in cardiac ventricles in the rat and in transplants

\begin{tabular}{|c|c|c|c|c|c|c|c|c|c|}
\hline \multirow[t]{2}{*}{ Tissue } & \multirow{2}{*}{$\begin{array}{l}\text { Age } \\
\text { (days) }\end{array}$} & \multirow{2}{*}{$\begin{array}{l}\text { Number of } \\
\text { cells }\end{array}$} & \multicolumn{6}{|c|}{ Percent } & \multirow{2}{*}{$\begin{array}{l}\text { Mean } \\
\text { ploidy }\end{array}$} \\
\hline & & & $\overline{2 c}$ & $2 c \times 2$ & $4 c$ & $4 c \times 2$ & $8 c$ & $8 c \times 2$ & \\
\hline \multirow[t]{5}{*}{ Ventricles } & 1 & 491 & 92.8 & 2.9 & 4.2 & - & - & - & $2.1 c^{a}$ \\
\hline & 1 & 100 & 90.0 & 2.0 & 8.0 & - & - & - & $2.2 c^{\mathrm{a}}$ \\
\hline & 1 & 434 & 93.6 & 2.4 & 4.0 & - & - & - & $2.1 c^{\mathrm{a}}$ \\
\hline & 35 & 150 & 10.6 & 75.3 & 4.0 & 4.7 & 0.7 & 4.7 & $4.2 c$ \\
\hline & 30 & 163 & 12.8 & 74.9 & 6.5 & 3.3 & 1.6 & 0.9 & $4.0 c$ \\
\hline \multirow[t]{5}{*}{ Transplants } & 35 & 353 & 37.7 & 48.7 & 12.5 & 0.8 & 0.3 & - & $3.3 c$ \\
\hline & 30 & 105 & 65.8 & 19.0 & 15.2 & - & - & - & $2.7 c$ \\
\hline & $33^{b}$ & 200 & 60.5 & 35.0 & 4.5 & - & - & - & $2.8 \mathrm{c}$ \\
\hline & 41 & 221 & 57.3 & 37.6 & 3.6 & 1.3 & - & 0.2 & $3.0 c$ \\
\hline & 35 & 389 & 51.1 & 42.4 & 5.9 & 0.6 & - & - & $3.0 c$ \\
\hline
\end{tabular}

among the $4 c$ myocytes, the majority are premitotic.

b Transplants from 20-day embryos.

acterized by many cytoplasmic processes. Sometimes they were star-shaped.

In month-old transplants substantial numbers of polyploid cells were detected. From scanning the preparations it was evident that many myocytes were binucleated; that is, they had at least four sets of chromosomes. On the average, about $40 \%$ of the cells were binucleated (Table I). Cytophotometry of the DNA characterized the polyploidy in greater detail (Table II). In transplants, from 34 to $62 \%$ of the myocytes were found to be nondiploid. The predominant class was binuclear $2 c \times 2$, but there were also some mononuclear tetraploid $4 c$ and isolated octaploid cells (see also Figs. 1 and 2). In transplants far more myocytes remained diploid than in the heart in situ, and there were significantly fewer cells with a high degree of ploidy. The mean ploidy of myocytes in month-old

\section{TABLE III}

Mean protein content of \pm S.E. in comparative units of naphthol yellow in $2 c \times 2$ myocytes in situ and in transplants

\begin{tabular}{lll}
\hline $\begin{array}{l}\text { Age } \\
\text { (days) }\end{array}$ & Ventricles & Transplants \\
\hline 1 & $333 \pm 13(24)^{a}$ & $378 \pm 10(70)$ \\
14 & & $648 \pm 22(124)$ \\
35 & $2160 \pm 112(103)$ & \\
\hline
\end{tabular}

a Number of cells in parentheses. rats is two times greater than that in one-day rats, but in month-old transplants it was only $1 \frac{1}{2}$ times greater.

About $2 \%$ of the myocytes in the one-day heart are already binucleated $(2 c \times 2)$. Approximately the same percentage was found in four-day transplants, but in addition to bidiploid cells, occasional octaploid $8 c$ myocytes were also found (Fig. 2). In both the one-day heart and four-day transplants, the usual picture of mitoses was seen. Fourteen-day transplants contained a significant number of non-diploid myocytes; however, at 21 or 30-41 days the number of such cells had not increased (Fig. 2). Starting at 14 days, mitoses were not seen in transplanted myocytes.

Of the myocytes synthesizing DNA in four-day transplants $\left(3 \mathrm{~h}\right.$ after the injection of $\left[{ }^{14} \mathrm{C}\right]$ thymidine), $92-98 \%$ were diploid and $0.8 \%$ were binucleated $2 c \times 2$ (Table IV). It is not clear how

\section{TABLE IV}

DNA-synthesizing and postmitotic myocytes of transplants (injection of $\left[{ }^{14} \mathrm{C}\right]$ thymidine into a ràt with a 4-day transplant)

\begin{tabular}{lccc}
\hline $\begin{array}{l}\text { Time between thymidine } \\
\text { injection and fixation }\end{array}$ & \multicolumn{3}{l}{ Number of labelled cells } \\
\hline & $2 c$ & $2 c \times 2$ & $4 c$ \\
$3 \mathrm{~h}$ & 577 & 5 & 30 \\
30 days & 189 & 37 & 2 \\
\hline
\end{tabular}




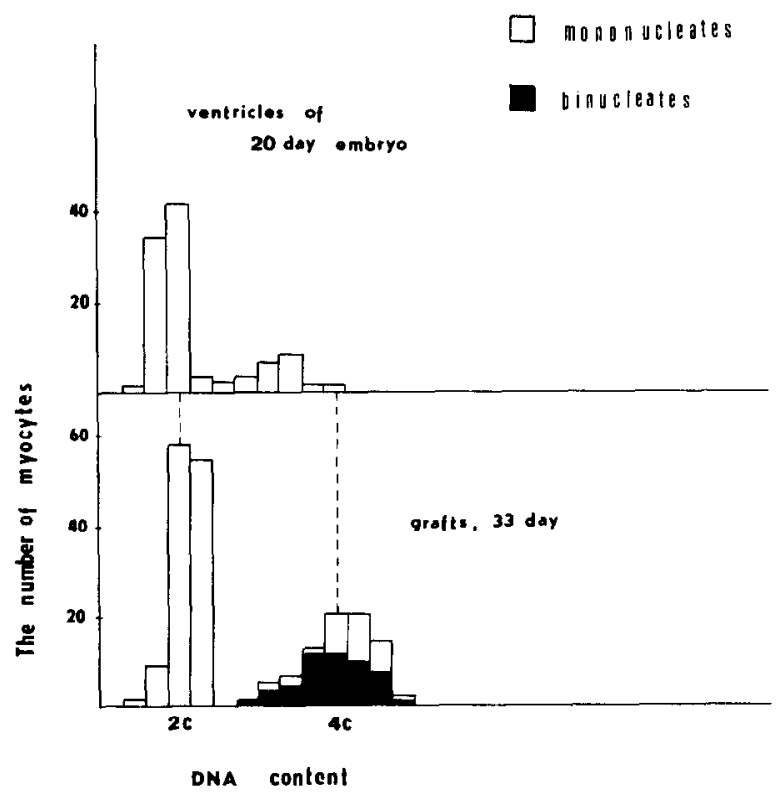

Fig. 3. Histograms of the quantity of DNA in the ventricle of the 20-day embryo and in grafts of 20-day embryonic myocytes 33 days after transplantation beneath the kidney capsule of a syngeneic adult rat.

many labelled cells had a stable tetraploid ( $4 n)$ genome; the majority of $4 c$ cells were, without a doubt, premitotic $G_{2}$ cells. Among the postmitotic cells (fixation 30 days after injection of $\left[{ }^{14} \mathrm{C}\right]$ thymidine into rats with 4-day transplants), $83 \%$ were diploid and $17 \%$ were polyploid myocytes. The intensity of labelling and density of the tracks in autoradiographs of the 4-day transplants was significantly greater than in many cells of the 30-day transplant.

In the heart of the 20-day embryo, binucleated myocytes were 10-20 times rarer than in newborn rats. The amount of DNA, like that in the histogram of the one-day heart, was characteristic of intensively proliferating myocytes (Fig. 3). In 33day transplants taken from the 20-day embryonic heart, about $40 \%$ polyploid myocytes, mainly binucleated $2 c \times 2$, were detected.

\section{Discussion}

The main result of this study was the demonstration of the polyploidization of cardiac myocytes in transplants beneath the kidney caps- ule. The set of classes of myocytes in transplants, including diploid, tetraploid and octaploid cells, did not differ from that which develops in situ. Polyploidization of the transplanted myocytes proceeded according to the same time schedule as that of the heart in situ. For mice and rats this occurs during the first 2-3 weeks after birth. The first binucleated myocytes are detected as early as in the 20-day embryo. On the day of birth the number of binucleated myocytes increases to 2-3\% of the total number of ventricular myocytes. Up to four days after birth the number of binucleated cells in situ does not increase, although there is much mitosis during this period. This attests to the fact that in rats, as well as in mice (Brodsky et al., 1985b), mitotic divisions predominate for the first days of life. In the rat, the polyploidization of ventricular myocytes in situ is completed by the end of the second week after birth (Kasten et al., 1982). In four-day ventricular transplants, a very small number of octoploid $8 c$ myocytes was found; this shows that polyploidization begins early, corresponding with the kinetics of polyploidization of the heart in situ. According to the autoradiographic results, $2 c \times 2$ cells were among the myocytes synthesizing DNA, and among the postmitotic cells there were already a number of polyploid cells, although the majority of cells at this time were still dividing. The reduction in the intensity of thymidine labelling of grafted myocytes from 4 to 30 days attests to the fact that many myocytes have by that time passed through two or three mitotic cycles. It is known that in the rat heart $2 c \times 2$ cells form as the result of acytokinetic mitosis of diploid cells, arising at the second or third generation of postnatal myocytes (Clubb and Bishop, 1984); this has also been shown for mice (Brodsky et al., 1980). By the second week after grafting of one-day ventricle, polyploidization was completed. The number of polyploidizing mitoses in transplants was less than in the heart in situ; octaploid cells were a great rarity in a transplant.

This experiment demonstrates that the program for the multiplication of the genome in cardiac myocytes is preserved after their transplantation into an ectopic site. This is reflected in the composition of the classes of myocytes which, over time, is qualitatively similar in situ and in trans- 
plants. However, quantitatively, the expression of polyploidy in transplants was markedly less than in the heart in situ.

Analysis of the appearance and amount of ploidy in transplants must take into account the different conditions in which the grafted ventricular myocytes develop. Not only are the myocytes removed from their usual hemodynamic load, but they are separated from the normal innervation and conduction system of the heart. In addition, by being transplanted into adult hosts, the myocytes are removed from the humoral environment (e.g., hormones and growth factors) of the neonatal body. The fact that the temporal qualitative program of polyploidization of the grafted ventricular myocytes is preserved, even in the body of an adult host, suggests that this is a reflection of an intrinsic property of the myocytes themselves, whereas the qualitative differences in the degree of binucleation and polyploidization are attributable to the differences in the functional and/or humoral environment to which the cells are exposed.

The possibility of non-specific influences on cells in general must be considered. For example, it has been shown that in old cultures of fibroblasts, binucleated and polyploid cells accumulate. These are rare both in young cultures and in situ (Kaji and Matsuo, 1981). However, in the transplants that we investigated the fibroblasts were diploid. Consequently, non-specific influences in this system were minimal.

The kinetics of polyploidization of myocytes in transplants were similar to those of the heart in situ. However, the genome of myocytes changes differently in vitro. Kasten (1972) long ago discovered acytokinetic mitosis of cardiac myocytes in culture. At that time it was not considered to be an important component of the program of polyploidization, but just a stoppage of the process. Polyploidizing mitoses arise and then repeat themselves in cultures, in distinction to the adult heart (Claycomb, 1983; Claycomb and Bradshaw, 1983). As a result cells with 8-10 nuclei appear; this is never seen in the heart of the rat or in transplants. Claycomb (1983) considers that the reaction of myocytes in vitro is a unique example of reactivation of mitotic genes. In transplants, in a reduced manner, the normal kinetics of proliferation are restored.

Two possible reasons for incomplete mitosis have been discussed (Brodsky and Uryvaeva, 1970, 1985): (1) genetic regulation, a change in the activity of the mitotic genes or (2) concurrent premitotic and tissue-specific synthesis, not allowing the cell to prepare itself completely for mitosis. Both mechanisms of incomplete mitosis are programmed in development. But in the first case it is a program of inactivation of the genes of mitosis; in the second, a program of intensification of tissue-specific processes, resulting in a redirection of resources of the cell, specializing toward the loss of proliferation.

A fundamental index of the differentiation of myocytes during the postnatal period is their growth - an enormous increase in mass. Thus, during the first year of life of a mouse the mean mass of cardiac myocytes increases by a factor of approximately 30 times after polyploidization has occurred (Brodsky et al., 1985b). $2 c \times 2$ myocytes of the hearts of 35-day-old rats were on the average 6.5 times heavicr than myocytes of the same ploidy of 1-day-old rats (Table III). Again, we should point out that such growth is peculiar to cells that have left the mitotic cycle. Newly formed tetraploid cells are two times heavier than diploid cells; the mean mass of diploid myocytes of 1-day rats is $170 \pm 8$ comparative units, whereas that of $2 c \times 2$ cells is $333 \pm 13$ units. In transplants, growth of the myocytes was considerably weaker after polyploidization. The mass of $2 c \times 2$ myocytes from 35-day transplants was only 1.9 times greater than that of myocytes in 1-day implants. It is important to note that during the first period after transplantation, when polyploidization occurred, the myocytes hardly grew (the mean increase in mass was $15 \%$ ).

One can propose that in transplanted ventricular myocytes, an inherent genetic program accounts for the quantitative expression of a patlern of polyploidization along a normal time schedule. However, its quantitative expression is significantly reduced (a range of $34-62 \%$ polyploidy in grafts vs. $90 \%$ in situ). Growth of the transplanted myocytes also appears to be highly influenced by their environment. 


\section{References}

Brodsky, V.Y. and I.V. Urivaeva: Development and properties of polyploid cell population in the ontogeny of mammals. Ontogenesis, Sov. J. Dev. Biol. 1, 181-195 (1970).

Brodsky, V.Y. and I.V. Urivaeva: Cell polyploidy: Its relation to tissue growth and function. Int. Rev. Cytol. 50, 275-332 (1977).

Brodsky, V.Y. and I.V. Urivaeva: Genome Multiplication in Growth and Development (Cambridge Univ. Press, London) 305 p. (1985).

Brodsky, V.Ya., A.M. Arefyeva and I.V. Uryvaeva: Mitotic polyploidization of mouse heart myocytes during the first postnatal week. Cell Tissue Res. 210, 133-144 (1980).

Brodsky, V.Y., G.V. Delone and N.N. Tsirekidze: Genome multiplication in cardiomyocytes of fast- and slow-growing mice. Cell Differ. 17, 175-181 (1985a).

Brodsky, V.Y., N.N. Tsirekidze and A.M. Arefyeva: J. Mol. Cardiol. 17, 445-455 (1985b).

Claycomb, W.C.: Cardiac muscle cell proliferation and cell differentiation in vivo and in vitro. Adv. Exp. Med. Biol. $161,249-265$ (1983).

Claycomb, W.C. and H.D. Bradshaw: Acquisition of multiple nuclei and the activity of DNA polymerase and reinitiation of DNA replication in terminally differentiated adult cardiac muscle cells in culture. Dev. Biol. 99, 331-337 (1983).

Clubb, F.Y. and S.P. Bishop: Formation of binucleated myocardial cells in the neonatal rat. Lab. Invest. 50, 571-577 (1984).

Kaji, K. and M. Matsuo: Aging of chick embryo fibroblasts in vitro. V. Time course studies on polyploid nucleus accumulation. Exp. Cell Res. 131, 410-412 (1981).

Kasten, F.H.: Rat myocardial cells in vitro: Mitosis and differentiated properties. In vitro 8, 128-149 (1972).

Kasten, F.H., B.N. Kudryavtsev and P.P. Rumyantsev: DNA content of isolated rat heart cells during postnatal development. J. Mol. Cell Cardiol. 14 (suppl. 1), 43-44 (1982).

Klinge, O.: Das Kernmuster im postnatalen Rattenherzen Funktion der mitotischen Aktivität. Verh. Dtsch. Ges. Pathol. 458-474 (1971).

Rakusan, K.: Cardiac growth, maturation and aging. In: Growth of the Heart and Disease, ed. R. Zak (Raven Press, New York) pp. 131-164 (1984).

Rumyantsev, P.P.: Interrelation of the proliferation and differentiation processes during cardiac myogenesis and regeneration. Int. Rev. Cytol. 51, 187-273 (1977).

Rumyantsev, P.P.: New comparative aspects of myocardial regeneration with special reference to cardiomyocyte proliferative behavior. In: Mechanisms of Cell Growth, ed. R.O. Becker (C.C. Thomas Publ, Springfield) pp. 311-342 (1981).

Tas, J., M. van der Ploeg, J.P. Mitchell and N.S. Cohn: Protein staining methods in quantitative cytochemistry. J. Microsc. $119,295-311$ (1980). 